\title{
ESTRUTURA DE CAPITAL E ASSIMETRIA DE INFORMAÇÃO: UM ESTUDO EM EMPRESAS BRASILEIRAS DE CAPITAL ABERTO DOS SETORES TÊXTIL E DE ENERGIA ELÉTRICA
}

Data de submissão: $21 / 03 / 2014$ Aceite: 16/07/2016

\author{
Natália Carolina Duarte de Medeiros ${ }^{1}$ \\ Francisval de Melo Carvalho ${ }^{2}$ \\ Caio Peixoto Chain ${ }^{3}$ \\ Gideon Carvalho de Benedicto 4 \\ Washington Santos da Silva ${ }^{5}$
}

\section{RESUMO}

Diante das diversas teorias a respeito da estrutura de capital e da teoria da Pecking Order, o presente trabalho buscou relacionar a assimetria de informação com a estrutura de capital das empresas, com o intuito de verificar se a assimetria de informação interfere na definição da estrutura do capital nas empresas brasileiras de capital aberto do setor de energia elétrica e têxtil. A pesquisa contou com uma amostra de 53 empresas, sendo 31 do setor de energia elétrica e 22 do setor têxtil, nos anos compreendidos de 2008 a 2012. A metodologia utilizada foi regressão com dados em painel, pois permite que a mesma unidade de corte transversal seja acompanhada ao longo do tempo. Os resultados apontaram que a assimetria de informação é um determinante da estrutura de capital, mas que os setores divergem entre si com relação à teoria da Pecking Order. No caso do setor de energia, a redução da assimetria de informação levou a uma propensão ao endividamento, enquanto no setor de têxtil ocorreu o inverso, visto que empresas menos passíveis de assimetria informacional são avessas ao endividamento.

Palavras-chave: Teoria da Pecking Order. Regressão com dados em painel. Efeitos fixos e aleatórios.

\footnotetext{
1 Possui graduação em Gestão Financeira pelo Instituto Federal Minas Gerais, IFMG, graduação em andamento em Administração pela Universidade de Franca, UNIFRAN e mestrado em Administração pela Universidade Federal de Lavras, UFLA. E-mail: nataliamedeiros15@hotmail.com

2 Possui graduação em Engenharia Agronômica pela Escola Superior de Agricultura de Lavras, ESAL, mestrado em Administração Rural pela ESAL, e Doutorado em Administração de Empresas, pela Universidade Presbiteriana Mackenzie, MACKENZIE. Lavras - MG - Brasil. E-mail: francarv@dae.ufla.br

3 Possui graduação em Ciências Econômicas pela Universidade Federal Rural do Rio de Janeiro, UFRRJ, mestrado em Administração pela Universidade Federal de Lavras, UFLA e doutorado em Administração pela UFLA. E-mail: caiopeixotochain@gmail.com

4 Possui Graduação em Ciências Contábeis pela Faculdade de Ciências e Letras de Campo Mourão, FACILCAM, mestrado em Ciências Contábeis e Atuariais pela Pontifícia Universidade Católica de São Paulo, PUC/SP, doutorado em Controladoria e Contabilidade pela Universidade de São Paulo, USP. Lavras - MG - Brasil. E-mail: gideon.benedicto@dae.ufla.br

5 Possui graduação em Economia pela Universidade Federal de Minas Gerais, UFMG, mestrado em Estatística e Experimentação Agropecuária pela Universidade Federal de Lavras, UFLA, doutorado em Estatística e Experimentação Agropecuária pela UFLA. Belo Horizonte - MG - Brasil. E-mail: washington.silva@ifmg.edu.br
} 


\section{INTRODUÇÃO}

A forma como as empresas definem sua estrutura de capital tem sido um assunto bastante discutido, porém, até o momento, não é possível identificar um único fator que possa ser considerado determinante para a estrutura de capital. Tal fato pode ser confirmado devido à quantidade de teorias que tentam explicar o que as empresas utilizam como referência ao escoIher as fontes para financiar suas atividades.

Modigliani e Miller (1958), em um primeiro estudo relacionado à estrutura de capital, construíram duas proposições: a primeira argumentava que o custo total de capital se mantinha inalterado qualquer que fosse o nível de alavancagem financeira, visto que o valor de uma empresa depende da qualidade dos seus ativos, e não da forma como ela é financiada. Essa proposição, no entanto, foi criada sob três hipóteses que refletem um mercado eficiente: 1) não há imposto de renda; 2 ) não há custos de falência, o que justifica o fato de que o custo de capital não se altera diante de elevados níveis de endividamento; e 3) há a possibilidade de os investidores realizarem a arbitragem no mercado.

Em um segundo estudo, Modigliani e Miller (1963) consideraram a existência do imposto de renda e o consequente benefício da dívida, reconsiderando que, mediante o uso da alavancagem financeira, é possível elevar o valor da empresa, reduzindo o custo total de capital. Vários estudos se sucederam a partir daí, indicando que certos fatores - como imperfeições existentes no mercado, custos de falência, custos de agência, entre outros - interferem na forma como as empresas financiam suas atividades.

Surgiram teorias como a do Free Cash Flow, que foca nas relações de agência e a do Trade-off, que pauta a decisão de financiamento na perspectiva da dívida, buscando uma estrutura ótima de capital (MYERS, 2001). Myers e Majluf (1984) e Myers (1984), por sua vez, destacaram em seus trabalhos que o fator determinante para a estrutura de capital é assimetria de informação, o que deu origem à teoria da Pecking Order.

A utilização de recursos provenientes de fontes em que não incidem, ou incidem com menos intensidade, assimetria de informação evitaria que a empresa incorresse em custos, como o custo de agência, abordado por Jensen e Meckling (1976).

Diante do impasse em relação aos fatores determinantes da estrutura de capital, se faz necessária a aplicação das teorias dentro do mercado brasileiro. Para tanto, o presente estudo teve como objetivo verificar se a assimetria de informação interfere na definição da estrutura do capital nas empresas brasileiras de capital aberto do setor de energia elétrica e têxtil no período de 2008 a 2012.

Este trabalho se justifica pela recorrente necessidade de pesquisa na área, com relação a empresas brasileiras. A teoria inicialmente desenvolvida por Myers e Majluf (1984) e Myers (1984) trata de um mercado diferente do brasileiro, em que características estruturais, e mesmo macroeconômicas, podem influenciar algo tão peculiar quanto a estrutura de capital. Dessa forma, pretendeu-se, por meio de estudo realizado nas empresas brasileiras de capital aberto dos setores de energia elétrica e têxtil, contribuir para o debate no que tange a estudos relacionados à estrutura de capital das empresas especificamente brasileiras, enfatizando e esclarecendo como a assimetria de informações interfere nesse processo. $O$ setor de energia elétrica foi o escolhido por Modigliani e Miller (1958) para compor a amostra que testou suas teorias, assim como no presente estudo.

Analisou-se também o setor têxtil como uma contraposição ao setor de energia, dadas as distintas características setoriais. Ademais, a escolha desses setores justifica-se pelo fato de 
serem dois setores de grande importância no contexto nacional: o setor de energia elétrica, considerando geração, transmissão e distribuição, faturou em 2012 o total de $R \$ 15,3$ bilhões, 17\% a mais que no ano de 2011 (ABINEE, 2013). Além disso, em 2011 esse setor apresentava um total de 123.013 postos de trabalho formais, número 15,6\% maior que o registrado em 2004 (DIESSE, 2013); o setor têxtil, por sua vez, alcançou a cifra de US\$ 58,2 bilhões em valores de produção e 1,7 milhões de empregos diretos no ano de 2012 (IEMI, 2013).

Contudo, vale destacar que esses dois setores vivem momentos diferentes em suas trajetórias econômicas: enquanto o setor de energia vive um momento de expansão, recebendo grandes aportes de capital por meio de financiamentos oferecidos por bancos como o BNDES (Bahnemann, 2013), o setor têxtil passa por uma crise causada pelo grande volume de importados oriundos de países asiáticos (DA COSTA; DA ROCHA, 2009). Essa discrepância no cenário econômico possibilitará verificar se, ainda assim, existem situações comuns nos dois setores envolvidos na análise, no que se refere à estrutura de capital e à assimetria de informação.

O período de análise foi em relação aos anos de 2008 a 2012. Segundo a ANA (Agência Nacional das Águas) (2014), os reservatórios do sudeste do país vêm apresentando quedas sucessivas mensais nos níveis de armazenamento desde 2013, afetando diretamente o setor. Diante disso, o período escolhido justifica-se pelo fato de que o estudo não seja afetado por essa situação.

\section{FUNDAMENTOS TEÓRICOS}

\subsection{Teoria da Agência}

Jensen e Meckling (1976), ao seguirem as ideais de Coase (1937), definem a empresa como sendo um nexo de contratos formais e informais, que servem para interligar e mediar as relações entre os indivíduos que compõem as organizações. Nesse sentido, os autores destacam que um desses contratos se caracteriza pela relação entre os provedores de capital (representados pelos proprietários e/ou acionistas) e os administradores e/ou gestores da entidade. Essa relação se dá pelo fato de que não é possível que os provedores de capital antecipem todas as situações decorrentes dos contratos, fazendo com que proprietários (principal) passem a responsabilidade das tomadas de decisões para o gestor (agente).

Ross (1973), ao estudar a remuneração dos gestores e a relação entre os interesses dos proprietários e dos administradores, argumenta que a relação de agência é antiga e comum, decorrente da interação social entre duas partes; quando uma (agente)é contratada para atuar representando os interesses da outra (principal). Com intuito de amenizar essa divergência, o principal pode atuar monitorando as atividades e decisões do agente, bem como oferecendo incentivos para que ele atue de acordo com seus interesses. No entanto, como destacado por Fama e Jensen (1983), não é possível haver monitoramento e oferecimento de incentivos sem que se incorraem custos, os quais são denominados custos de agência (JENSEN; MECKLING, 1976).

\subsection{Governança Corporativa}

Apesar de parecer um assunto recente, a governança corporativa já é antiga e está ligada às relações de agência abordada por Jensen e Meckling (1976). A governança corporativa pode ser entendida como um conjunto de mecanismos de controle, interno e externo, e de incentivos, que tem como objetivo minimizar os custos decorrentes do problema de agência (SHLEIFER; VISHNY, 1997; SILVEIRA, 2006; SILVEIRA; PEROBELLI; BARROS, 2008). 
De acordo com Gugler e Yurtoglu (2003), existem dois principais conflitos com os quais a governança corporativa procura lidar: aquele entre o acionista controlador e os acionistas minoritários, e aquele entre o agente e os acionistas. Andrade e Rosseti (2004) afirmam ainda que as práticas de governança devem ser capazes de atuar também naqueles conflitos originados por uma dispersão de propriedade e de um sistema de controle que não seja adequado.

\subsection{Assimetria de informação}

Como ressaltam Milgrom e Roberts (1992), a informação normalmente é distribuída de forma imperfeita entre os agentes, o que impossibilita o equilíbrio do mercado proposto pelas teorias tradicionais, permitindo novas formas de entendimento sobre o surgimento de certos tipos de falhas de mercado.

Em situações em que ocorrem assimetrias de informação ex post, ou seja, quando um agente detém mais informação que outros agentes envolvidos na transação depois do fechamento do contrato, surge a possibilidade de que esse agente melhor informado não se comporte de forma eficiente como previsto. Essa situação é chamada de risco moral (WILLIAMSON, 1985). Em relação a situações pré-contratuais, ex ante, em que uma das partes envolvidas detém mais informações antes da realização do contrato, surge o problema da seleção adversa, o que possibilita que a parte melhor informada insira no contrato questões em seu benefício. Essas duas situações são consideradas como oportunismo, problema decorrente da assimetria de informação (WILLIAMSON, 1985).

Diante da questão da assimetria informacional, surge uma corrente que aborda a assimetria como determinante da estrutura de capital. De acordo com Myers e Majluf (1984) e Myers (1984), precursores dessa teoria, a estrutura de capital é utilizada como forma de atenuar os problemas ocasionados pela assimetria de informação nas decisões de financiamento da empresa. A partir disso, os autores desenvolvem uma hierarquia em relação às fontes de financiamento preferíveis pelas empresas.

\subsection{Estrutura de Capital}

Um dos temas centrais e mais debatidos em finanças é a estrutura de capital. Entende-se por estrutura de capital a forma e a proporção com que as empresas utilizam o capital próprio e o capital de terceiro para financiar as suas atividades (BRITO; CORRAR; BATISTELLA, 2007). De maneira geral, o capital próprio é aquele fornecido pelos sócios e/ou acionistas, e o capital de terceiro é aquele obtido por meio de dívidas (ASSAF NETO, 2003).

Dessa forma, seria vantajoso para a empresa a utilização apenas de dívidas, tendo em vista o benefício fiscal gerado pela alavancagem. Essa afirmação, porém, não é verificada na prática, pois, como ressaltam Famá e Grava (2000), um nível elevado de endividamento pode ocasionar problemas à empresa, dado o risco de insolvência diante das altas despesas financeiras. Essa questão, então em aberto, deu origem a uma discussão sobre o assunto e ao surgimento de vários estudos acerca da estrutura de capital.

Myers (2001) faz um panorama das teorias que tentam explicar os fatores que direcionam as decisões de financiamento das empresas, destacando principalmente as teorias do Free Cash Flow, Trade-off e Pecking Order. Essa última é tratada com mais atenção, visto que o objetivo de pesquisa é verificar se a assimetria de informação- fator central da teoria da Pecking Order - interfere na estrutura de capital das empresas brasileiras de capital aberto do setor de energia elétrica e têxtil. 


\subsection{Teoria da Pecking Order}

A teoria da Pecking Order (POT), de Myers e Majluf (1984) e Myers (1984), não assume a existência de uma estrutura ótima de capital, mas prediz a existência de uma ordem hierárquica para a escolha de financiamento da empresa: primeiro são utilizados os recursos gerados internamente (retenção de lucros); em segundo, a emissão dos títulos de dívidas; e, por último, a emissão de ações. Essa hierarquia é baseada na ideia de que toda ação da empresa gera um sinal ao mercado, onde a utilização de recursos menos passíveis de assimetria informacional são preferíveis.

Os recursos gerados internamente, ou seja, obtidos por meio da retenção de lucros, não carregam custos de transação e não correspondem à assimetria de informação, além de que se assume que empresas mais lucrativas tendem a ter mais recursos disponíveis, não precisando então recorrer a financiamentos e incorrer ao risco de um alto nível de endividamento (MYERS, 1984; MYERS; MAJLUF, 1984).

Para Myers (1984), quando a empresa não dispuser de fluxo de caixa interno para financiar seus dispêndios de capital, ela recorrerá à emissão de títulos de dívidas. Isso porque, sempre que a empresa lança a informação de que está emitindo títulos de dívida, o mercado avalia como um sinal positivo, demonstrando que a empresa está em crescimento e apta a captar financiamentos. A utilização de tal mecanismo pode ser benéfica também no que tange à assimetria de informações. Ao captar dívidas, os credores exigem informações relativas à empresa, para que possa ser corretamente avaliada, evitando erros no contrato. Tal fato diminui a assimetria informacional entre os gestores e os credores (DANTAS; SOUZA, 2008).

No fim da ordem hierárquica, encontra-se a emissão de ações. Ao emitir ações, a empresa sinaliza ao mercado uma informação negativa. Pela assimetria de informação existente, os investidores podem ter menos informação sobre o valor da empresa que os gestores, indicando que os preços das ações podem ser subavaliados pelo mercado (MYERS; MAJLUF, 1984).

\subsection{Evidências Empíricas}

Não existe um consenso sobre os determinantes da estrutura de capital, seja a assimetria informacional, abordada pela $P O T$, ou outros fatores. Alguns achados na literatura são apresentados a seguir.

Albanez e Valle (2009) buscaram identificar se a assimetria informacional influencia na forma de financiamento das empresas brasileiras. $O$ estudo foi realizado com empresas brasileiras de capital aberto, entre 1997 e 2007, utilizando da metodologia de dados em painel. Como forma de mensurar a assimetria de informação, os autores utilizaram como proxies às variáveis empresas listadas nos níveis de governança corporativa, empresas que emitiram ações ou títulos (ADR's) na bolsa de Nova lorque (NYSE), empresas listadas para o troféu de transparência, liquidez na bolsa, volatilidade e intensidade do negócio. Os autores ainda utilizaram as variáveis tamanho, tangibilidade, intangibilidade, rentabilidade e risco como variáveis de controle. Como variável dependente, os autores assumiram as variáveis ligadas à estrutura de capital. O principal resultado apontou que empresas com menor nível de assimetria de informação se endividam mais, contrariando a teoria do Pecking Order.

Frank e Goyal (2003), em estudo com uma ampla amostra de empresas americanas no período de 1971 a 1998, encontraram evidências que contrariam a teoria da POT ao aplicar o método de regressão múltipla. 
Fama e French (2002) realizaram um estudo para verificar qual teoria melhor se aplicava à realidade. Concluíram que tanto a teoria do Trade-off quanto a Pecking Order são aplicadas, dependendo da situação em que a empresa se encontra. Os resultados foram encontrados por meio de regressões múltiplas que buscaram compreender os comportamentos dos dividendos e da alavancagem.

Nakamura et al. (2007), em estudo realizado no Brasil no período de 1999 a 2003, concluíram que tanto a teoria da Pecking Order quanto a teoria do Trade-off são aplicáveis na realidade brasileira. A amostra utilizada no estudo foi composta por 91 empresas de capital aberto e o método utilizado foi o modelo de dados em painel, em que as variáveis dependentes utilizadas são proxies da alavancagem financeira, identificadas pelo endividamento de mercado e endividamento contábil. Já com relação às variáveis independentes, foram utilizadas aquelas que os autores consideraram como proxies dos diferentes determinantes da estrutura de capital, sendo elas: Liquidez corrente, Tamanho da empresa, Rentabilidade, Crescimento esperado pelo diferencial do valor de mercado, Risco do negócio medido pela volatilidade de lucros, economia fiscal e crescimento de vendas.

Famá, Barros e Silveira (2001) realizaram estudo com 68 empresas do mercado norte americano, além de 33 empresas latinas americanas, todas do setor de energia elétrica. Foi aplicado o modelo de regressão múltipla e os resultados também apontaram que a Pecking Order foi a corrente dominante para a estrutura de capital das empresas da amostra.

\section{METODOLOGIA}

\subsection{Amostra e Fonte de Dados}

A amostra utilizada compreende as empresas brasileiras de capital aberto dos setores de energia elétrica e têxtil listadas na Bovespa, com dados dos anos de 2008 a 2012. Os dados foram coletados por meio do banco de dados Economática. Ao final da filtragem, a amostra contou com um total de 53 empresas, sendo 31 do setor de energia elétrica e 22 do setor têxtil. Foram excluídas as empresas que não apresentaram dados para os 5 anos consecutivos de análise e aquelas que não contemplavam todas variáveis necessárias para a análise.

No setor de energia elétrica, as 31 empresas incluídas na amostra representam 75,6\% do total de empresas do setor listadas na Bovespa. Do total de 31 empresas da amostra, de acordo com o ranking da revista Exame, estão incluídas 4 das 5 empresas que mais cresceram e as 5 empresas que mais faturaram no ano de 2012. Com relação ao setor têxtil, a representatividade das 22 empresas da amostra atinge aproximadamente $81,5 \%$ do total de empresas listadas na Bovespa no setor. Da mesma forma que o setor de energia, de acordo com o ranking da revista Exame, 4 das 5 empresas que mais cresceram no setor estão incluídas na amostra, bem como as 5 empresas do setor que mais faturaram no ano de 2012.

Dados relativos às proxies de assimetria de informação foram coletados por meio do Sistema de Divulgação Externa da Comissão de Valores Mobiliários (DIVEX/CVM).

\subsection{Variáveis}

\subsubsection{Mensuração da Assimetria de Informação}

Tendo em vista a dificuldade de obtenção direta de dados referentes à assimetria de informação, a mensuração se deu por meio de proxies. Tais proxies são identificadas em trabalhos 
semelhantes e recentes, como o de Iquiapaza, Lamounier e Amaral (2007) e o de Albanez e Valle (2009). Esses autores assumem em seus trabalhos variáveis categóricas (dummies) em que o valor 1 corresponde a empresas que apresentam a condição de valor em questão, e 0 em outros casos, além das variáveis numéricas. Dessa forma, utilizou-se as seguintes variáveis independentes, em forma de variáveis categóricas, com intuito de mensurar a assimetria de informação:

- GC: empresas que estão listadas em algum nível de governança corporativa, podendo ser Nível 1, Nível 2 ou Novo Mercado. Essa variável foi utilizada em trabalhos como o de Iquiapaza, Lamounier e Amaral (2007) e Albanez e Valle (2009). Segundo esses autores, aderir a algum nível de governança corporativa exige que as empresas divulguem uma maior quantidade de informações, fato que reduz a assimetria informacional;

- DE: diretor executivo (CEO) e presidente do conselho de administração são pessoas diferentes. Almeida et al. (2013) argumentam que, quando o presidente executivo da empresa e o presidente do conselho são pessoas diferentes, se evita a concentração de controle e, consequentemente, a assimetria de informação entre os gestores e as demais partes interessadas;

- ANEFAC: empresas ganhadoras do Troféu Transparência, realizado pela ANEFAC(Associação Nacional dos Executivos de Finanças Administração e Contabilidade), que premia as empresas com as melhores práticas contábeis e o conjunto de informações mais objetivas para o mercado. Dessa forma, como tratado por Albanez e Valle (2009), tem-se uma importante variável, visto que quanto mais transparência, menos assimetria informacional;

- ADR: empresas que emitiram ações ou títulos no mercado americano (ADR's) na bolsa de valores de Nova lorque (NYSE). De acordo com Iquiapaza, Lamounier e Amaral (2007), o acesso ao mercado americano faz com que a empresa tenha uma necessidade e um rigor maior de divulgação de informações, o que diminui a assimetria de informação;

- TCA: total de membros no conselho de administração. A utilização dessa variável justifica-se pelo fato de que quanto maior a quantidade de membros no conselho, menos passível é a empresa de sofrer assimetria de informação. Isso porque, de acordo com IBGC (2010), a função do conselho é valorizar e proteger a organização, buscando o equilíbrio entre os anseios das partes interessadas;

- Indep.: percentual de conselheiros independentes no conselho de administração. A utilização dessa variável justifica-se pelo fato de que entende-se que quanto maior a quantidade de conselheiros independentes, menos passível a assimetria de informação a empresa se encontra. Isso porque, segundo o IBGC (2010), quanto maior a quantidade de conselheiros independentes, mais enquadrada às boas práticas de governança corporativa a empresa estará;

- Total1: percentual total de ações nas mãos do maior acionista. A utilização dessa variável se dá pelo fato de que empresas com ações muito concentradas tendem a ser mais passíveis de assimetria de informação, visto que o acionista majoritário tem possibilidade maior de ter informações privilegiadas em relação a outros acionistas minoritários. Variável semelhante foi utilizada nos trabalhos de Procianoy e Schnorrenberger (2004). 


\subsubsection{Variáveis de Controle}

Albanez e Valle (2009) e Iquiapaza, Lamounier e Amaral (2007) destacam que as variáveis de controle são importantes determinantes da estrutura de capital das empresas por representarem importantes atributos específicos das entidades. Dessa forma, foram utilizadas as seguintes variáveis:

- Tamanho: calculada pelo logaritmo natural do ativo total. Brito, Corrar, Batistella (2007) argumentam que o tamanho da empresa pode ter impacto na sua estrutura de capital, indicando que, no caso do mercado brasileiro, grandes empresas têm mais acesso a crédito de longo prazo do que empresas pequenas. A variável foi logaritimizada para reduzir possíveis problemas nos modelos ocasionados pela discrepância desses valores de uma empresa em relação a outra;

- Risco: coeficiente Beta no ano t. Halov e Heider (2003) destacam que o risco reduz a capacidade de dívida e aumenta o seu custo, demonstrando então uma relação inversa entre risco e endividamento;

- Juros: taxa de juros no ano (representada pela taxa básica de juros, a SELIC).Apesar de não se caracterizar como um atributo específico da empresa, a taxa de juros foi incluída como variável de controle porque a taxa de juros do mercado brasileiro se diferencia de um mercado desenvolvido, como o americano, no qual a teoria da Pecking Order foi desenvolvida. Diante disso, pode-se assumir que a taxa de juros alta dificulta o acesso à alavancagem, indicando uma relação negativa com o endividamento;

- Rentabilidade: rentabilidade do ativo, calculada pela relação lucro operacional dividido pelo ativo total. Halov e Heider (2003) destacam que empresas maiores tendem a ter uma imagem melhor perante aos credores, o que facilita o acesso ao mercado de dívidas com condições melhores;

- Liquidez: liquidez na Bovespa. Bharath, Pasquariello e Wu (2009) afirmam que a liquidez pode estar relacionada à assimetria de informação. Para esses autores, quanto maior a liquidez, menor a assimetria, o que leva ao não endividamento.

\subsubsection{Estrutura de Capital}

Tendo em vista a verificação da influência da assimetria de informação na definição da estrutura de capital, essa foi representada pela variável Dívida, calculada por dívida bruta / ativo total. A escolha dessa variável, que foi aqui tratada como a variável dependente, decorre do fato de que empresas com alto endividamento apresentam alta proporção entre dívida bruta e ativo total.

\subsubsection{Análise de dados em painel}

De acordo com Gujarati (2006), os painéis se configuram em duas formas: o balanceado e não balanceado. $O$ painel balanceado é aquele em que se tem os mesmos $T$ períodos para as mesmas unidades de corte transversal $N$. Já no caso do painel não balanceado, algumas unidades de corte transversal não apresentam alguns períodos de análise.

Para o tratamento dessas duas configurações de painéis, Wooldridge (2006) destaca os efeitos fixos e os efeitos aleatórios. O modelo de efeitos fixos é aplicado diretamente a painéis não balanceados. Esse modelo permite que o intercepto varie para cada unidade de corte trans- 
versal, respeitando as características específicas de cada uma, mas assume-se que os coeficientes angulares são constantes entre elas. $O$ estimador dos efeitos fixos considera uma correlação arbitrária, características não observadas de cada unidade de corte transversal e as variáveis independentes em qualquer período de tempo. Quanto aos efeitos aleatórios, ao contrário dos efeitos fixos, esse assume que as características não observadas são correlacionadas com as variáveis explicativas. A equação genérica é demonstrada a seguir.

$$
Y_{\text {it }}=\beta_{0 i}+\beta_{1} X_{1 i t}+\beta_{2} X_{2 i t}+\beta_{3} X_{3 i t}+u_{i t}
$$

Gujarati (2006) salienta ainda que a diferença entre os dois modelos é, no caso de efeitos fixos, que cada unidade de corte transversal tem o seu próprio valor de intercepto, $\beta_{0}$ ' todos $\mathrm{N}$ valores para $\mathrm{N}$ unidades de corte transversal. Já nos efeitos aleatórios, o intercepto ${ }^{\beta_{0}}$ representa o valor médio de todos os interceptos de corte transversal e o elemento erro representa o desvio aleatório do intercepto individual de seu valor médio. A regra de decisão é realizada por meio do teste de Hausman, o qual assume como hipótese nula que as diferenças entre os efeitos fixos e aleatórios não é sistemática. No caso de haver diferenças entre os dois modelos, ela é interpretada como uma evidência em favor dos efeitos fixos, rejeitando assim a hipótese nula.

Ainda de acordo com Gujarati (2006, p. 514), a utilização do método de dados em painel apresentam várias vantagens, dentre elas "dados mais informativos, mais variabilidade e menos colinearidade entre as variáveis." A mesma situação é destacada por Hsiao (1986), que diz que a colinearidade entre as variáveis independentes sofre redução.

Para tratamento dos dados, foi utilizado o software Stata versão 12.

\section{RESULTADOS E DISCUSSÃO}

\subsection{Análise de Dados em Painel}

\subsubsection{Setor de energia}

No setor de energia elétrica, o teste de Hausman, com $p-$ valor 0,0002 , apontou que o melhor modelo a ser utilizado seria o de efeitos fixos. Foram aplicados o teste de Wald para detecção de heterocedasticidade, o teste de Wooldridge para detecção de autocorrelação, e a análise do fator de inflação da variância para detectar problemas de multicolinearidade, como destacado por Gujarati (2006). O resultados para detecção de multicolinearidade são mostrados no quadro 1.

Quadro 1 - Fator de Inflação da Variância para setor de energia

\begin{tabular}{|c|c|}
\hline Variável & VIF \\
\hline Juros & 1.05 \\
\hline Risco & 1.04 \\
\hline Rentabilidade & 1.36 \\
\hline Tamanho & 2.36 \\
\hline Liquidez & 1.66 \\
\hline TCA & 1.83 \\
\hline Indep & 1.14 \\
\hline ADR & 2.75 \\
\hline DE & 1.25 \\
\hline ANEFAC & 1.17 \\
\hline GC & 2.14 \\
\hline Total1 & 2.39 \\
\hline
\end{tabular}

Fonte: Elaborado pelos autores, 2013. 
De acordo com o Quadro 1, nota-se que nenhuma variável apresentou problemas de multicolinearidade, visto que todos os valores obtidos foram inferiores a 10.

$\mathrm{O}$ teste de Wald utilizado para detectar problemas de heterocedasticidade em painéis de efeitos fixos assume como hipótese nula que os dados são homocedásticos. O resultado do teste, analisado através do $p$-valor $(0,00)$, ofereceu subsídios para rejeitar a hipótese nula. $\mathrm{O}$ teste de Wooldridge, por sua vez, foi utilizado para detectar problemas de autocorrelação e assumiu como hipótese nula a ausência de autocorrelação. O resultado do teste com $p$-valor 0,00 rejeitou a hipótese nula. Diante dos resultados obtidos nos testes, os modelos foram corrigidos utilizando a metodologia de Newey e West (1987), um estimador robusto tanto na presença de heterocedasticidade quanto na de autocorrelação.

Foram estimados nove modelos. Os sete primeiros contaram com as variáveis de controle e uma variável proxy da assimetria de informação, enquanto o modelo oito foi composto por todas as variáveis de controle: Juros, Risco, Rentabilidade, Tamanho e Liquidez, além das variáveis proxies da assimetria, que são TCA, Indep, ADR, DE, ANEFAC, GC e Total1. O último modelo, por sua vez, contou apenas com as variáveis proxies da assimetria de informação, como visto a seguir.

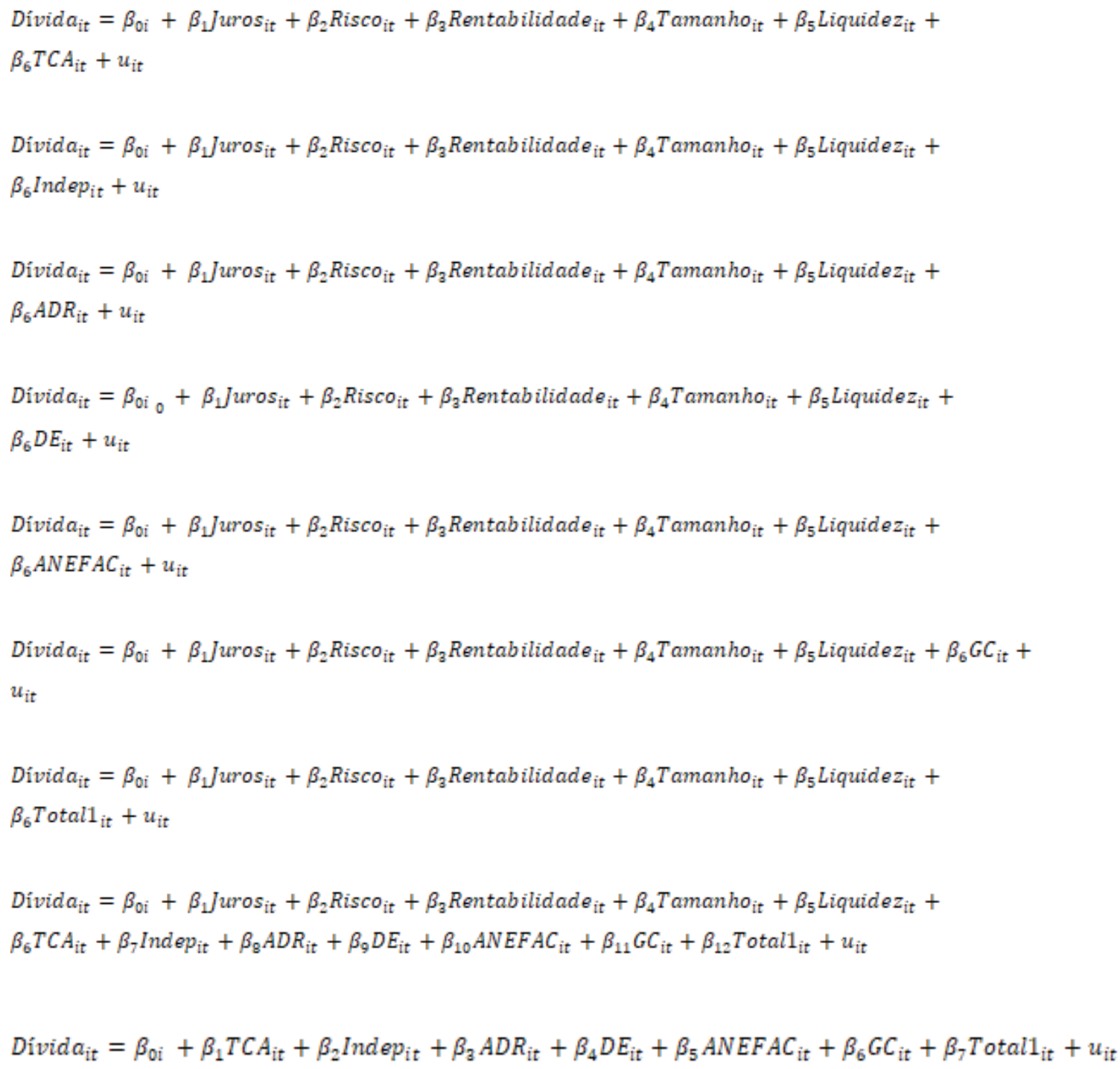


O intuito da estimação dos sete primeiros modelos foi verificar o efeito isolado de cada proxy, juntamente com as variáveis de controle. Esses modelos buscaram evidenciar o comportamento conjunto das variáveis proxy de forma gradativa. O modelo oito, por sua vez, contou com todas as variáveis de controle e proxies, com intuito de verificar como as variáveis se comportam em conjunto. $\mathrm{O}$ modelo nove foi construído apenas com as variáveis proxies para verificar se a assimetria de informação, representada por elas, interfere na estrutura de capital das empresas.

A Tabela 1 contempla a saída dos modelos de regressão de dados em painel com efeitos fixos para empresas que compuseram a amostra do setor de energia elétrica. 
Tabela 1 - Modelo de Dados em Painel com efeitos fixos com correção de Newey e West. Variável dependente: Dívida.

\begin{tabular}{|c|c|c|c|c|c|c|c|c|c|c|c|c|c|c|c|c|c|c|}
\hline \multirow[b]{2}{*}{$\begin{array}{l}\text { Variáveis Inde- } \\
\text { pendentes }\end{array}$} & \multicolumn{2}{|c|}{ Equação (1) } & \multicolumn{2}{|c|}{ Equação (2) } & \multicolumn{2}{|c|}{ Equação (3) } & \multicolumn{2}{|c|}{ Equação (4) } & \multicolumn{2}{|c|}{ Equação (5) } & \multicolumn{2}{|c|}{ Equação (6) } & \multicolumn{2}{|c|}{ Equação (7) } & \multicolumn{2}{|c|}{ Equação (8) } & \multicolumn{2}{|c|}{ Equação (9) } \\
\hline & Coef. & $\begin{array}{l}\text { p-va- } \\
\text { lor }\end{array}$ & Coef. & $p$-valor & Coef. & $\begin{array}{c}\text { p-va- } \\
\text { lor }\end{array}$ & Coef. & $\begin{array}{c}\text { p-va- } \\
\text { lor }\end{array}$ & Coef. & p-valor & Coef. & $\begin{array}{c}\text { p-va- } \\
\text { lor }\end{array}$ & Coef. & $p$-valor & Coef. & $\begin{array}{c}\text { p-va- } \\
\text { lor }\end{array}$ & Coef. & $\begin{array}{l}\text { p-va- } \\
\text { lor }\end{array}$ \\
\hline Juros & -0.25 & 0.603 & -0.37 & 0.430 & -0.36 & 0.463 & -0.32 & 0.509 & -0.36 & 0.474 & -0.46 & 0.351 & -0.31 & 0.525 & -0.26 & 0.558 & & \\
\hline Risco & -0.03 & 0.000 & -0.03 & 0.000 & -0.02 & 0.000 & -0.03 & 0.000 & -0.02 & 0.000 & -0.03 & 0.000 & -0.04 & 0.000 & -0.05 & 0.000 & & \\
\hline Rentabilidade & -0.08 & 0.615 & -0.21 & 0.226 & -0.12 & 0.508 & -0.17 & 0.350 & -0.10 & 0.555 & -0.04 & 0.784 & -0.13 & 0.449 & -0.31 & 0.091 & & \\
\hline Tamanho & 5.217 & 0.000 & 3.572 & 0.000 & 3.795 & 0.001 & 3.31 & 0.006 & 4.02 & 0.000 & 5.08 & 0.000 & 5.33 & 0.000 & 3.57 & 0.015 & & \\
\hline Liquidez & -7.45 & 0.407 & -1.38 & 0.857 & -5.74 & 0.447 & -3.18 & 0.695 & -4.30 & 0.595 & 0.13 & 0.990 & -4.13 & 0.642 & -0.60 & 0.949 & & \\
\hline TCA & -0.89 & 0.109 & & & & & & & & & & & & & -1.17 & 0.804 & 0.27 & 0.706 \\
\hline Indep & & & 0.467 & 0.000 & & & & & & & & & & & 0.34 & 0.000 & 0.33 & 0.000 \\
\hline ADR & & & & & 9.992 & 0.001 & & & & & & & & & 14.92 & 0.000 & 16.99 & 0.000 \\
\hline $\mathrm{DE}$ & & & & & & & 12.89 & 0.001 & & & & & & & 12.29 & 0.000 & 16.26 & 0.000 \\
\hline ANEFAC & & & & & & & & & 5.78 & 0.050 & & & & & -1.94 & 0.621 & -2.69 & 0.587 \\
\hline GC & & & & & & & & & & & -5.47 & 0.110 & & & -2.83 & 0.441 & -0.43 & 0.878 \\
\hline Total1 & & & & & & & & & & & & & 0.14 & 0.012 & 0.12 & 0.099 & 0.06 & 0.350 \\
\hline Constante & -40.98 & 0.025 & -64.78 & 0.000 & -25.76 & 0.161 & -29.86 & 0.096 & -29.28 & 0.110 & -43.02 & 0.021 & -57.42 & 0.004 & -71.05 & 0.001 & -23.74 & 0.036 \\
\hline \multirow[t]{2}{*}{ Observações } & \multicolumn{2}{|c|}{155} & \multicolumn{2}{|c|}{155} & \multicolumn{2}{|c|}{155} & \multicolumn{2}{|c|}{155} & \multicolumn{2}{|c|}{155} & \multicolumn{2}{|c|}{155} & \multicolumn{2}{|c|}{155} & \multicolumn{2}{|c|}{155} & \multicolumn{2}{|c|}{155} \\
\hline & \multicolumn{2}{|c|}{ Equação (1) } & \multicolumn{2}{|c|}{ Equação (2) } & \multicolumn{2}{|c|}{ Equação (3) } & \multicolumn{2}{|c|}{ Equação (4) } & \multicolumn{2}{|c|}{ Equação (5) } & \multicolumn{2}{|c|}{ Equação (6) } & \multicolumn{2}{|c|}{ Equação (7) } & \multicolumn{2}{|c|}{ Equação (8) } & \multicolumn{2}{|c|}{ Equação (9) } \\
\hline$F$ (p-valor) & \multicolumn{2}{|c|}{0.000} & \multicolumn{2}{|c|}{0.000} & 0.0 & & 0.0 & & 0.0 & 00 & 0.0 & & 0.0 & 00 & 0.0 & & 0.0 & \\
\hline
\end{tabular}


Observando a Tabela 1, é importante destacar que a estatística $F$, representada nesse caso pelo $p$-valor, rejeitou a hipótese nula de que o efeito conjunto das variáveis explicativas na variável dependente é nulo a um nível de significância de $1 \%$ para todos os modelos.

Vale destacar a utilização do modelo nove. Tal modelo é restrito às variáveis proxies da assimetria de informação e teve o intuito de verificar se de fato essas variáveis interferem na estrutura de capital das empresas. $O$ resultado do $p$-valor da estatística $F$ foi significativo a $1 \%$, indicando que o efeito conjunto das variáveis explicativas (que, nesse caso, refletem a assimetria de informação) na variável dependente não é nulo, confirmando que essas variáveis exercem influência na variável que reflete a estrutura de capital das empresas.

Passando para a análise das variáveis, nota-se que os coeficientes das variáveis Juros, Rentabilidade e Liquidez não foram significativos em nenhum dos modelos, não sendo passíveis de interpretação nessa situação. Nesse estudo, os coeficientes foram considerados significativos levando em conta $p$-valores inferiores a 0,10 . Tal escolha remete ao fato de que na econometria normalmente é considerada a significância de $1 \%, 5 \%$ ou no máximo $10 \%$, como destacado por Gujarati (2006).

Com relação às outras variáveis de controle, o coeficiente variável Risco, representada pelo Beta das empresas da amostra, foi significativo a $1 \%$ em todos os modelos em que foi inserida, com coeficiente em torno de -0.03 . Tal relação negativa confirma o que era esperado e corrobora os estudos de Halov e Heider (2003). A justificativa está no fato de que o risco dificulta o acesso à alavancagem, tornando a dívida mais cara e menos viável.

A outra variável de controle que apresentou coeficiente significativo em todos os modelos foi o Tamanho, representada pelo logaritmo natural do ativo total, com significância de $1 \%$ nos sete primeiros modelos e $5 \%$ no último. $O$ coeficiente que foi positivo em todas as situações variou entre 5.33 e 3.31. O resultado encontrado se mostrou dentro do esperado, isso porque, como destacado por Halov e Heider (2003), entende-se que empresas maiores tenham "melhor reputação" e, consequentemente, mais acesso e facilidade ao endividamento que empresas menores.

O resultado encontrado corrobora os achados de Harris e Raviv (1991), Brito et al. (2007) e Albanez e Valle (2009), além de ir ao encontro do que foi obtido pela análise de correlação, que estabeleceu uma relação positiva entre a variável independente tamanho e a variável dependente dívida. O resultado encontrado fica ainda mais evidente ao se levar em conta o setor em questão. Nesse caso, empresas maiores têm melhor reputação, menos risco de falência e estão mais aptas frente aos credores a captar empréstimos, principalmente em se tratando de um mercado em que a alavancagem tem sido bastante facilitada, como destacado por Bahnemann (2013) e Ventura Filho (2013). Esse é o caso do setor de energia.

Com relação às variáveis proxies da assimetria de informação, vale destacar inicialmente que a variável TCA, que indica o total de conselheiros do conselho de administração, e a variável GC, que indica as empresas que aderem a algum nível de governança corporativa, não foram significativas em nenhum dos dois modelos aos quais foram inclusas.

A variável Indep, que indica a porcentagem de conselheiros independentes do conselho de administração, teve coeficiente significativo a $1 \%$ nos três modelos em que foi incluída. $O$ coeficiente foi positivo em todos os casos, indicando que empresas com maior quantidade de conseIheiros independentes tendem a se endividar mais. Tal situação contraria o esperado, pois, como ressaltado pelo Manual de Boas Práticas de Governança Corporativa (IBGC, 2010), quanto maior a quantidade de conselheiros independentes, menor é a possibilidade de que o conselho seja "contaminado" pelos interesses da administração. Sendo assim, a empresa seria menos passível de assimetria de informação. Esse resultado, porém, foi consistente com o encontrado na análise 
de correlação entre essa proxy e a variável dependente. A explicação para essa situação pode estar no fato de que uma redução na assimetria de informação leva ao mercado mais informações sobre a empresa, facilitando a avaliação por parte de credores. O aumento do endividamento pode ser explicado, então, pelo momento vivenciado pelo setor de energia: uma fase de grande oferta de financiamentos, facilitando o acesso à alavancagem, como relatado na seção 2.8 .

A variável binária ADR também apresentou coeficiente estatisticamente significativo nos três modelos em que foi inclusa, com nível de significância de $1 \%$ nos três modelos. O coeficiente não foi o esperado, pois, como destacado por lquiapaza, Lamounier e Amaral (2007), entende-se que empresas que emitem ADR's (ações ou títulos no mercado americano) são mais transparentes em decorrência da maior exigência de rigor das informações pelo mercado americano, o que diminui a assimetria informacional. Contudo, Albanez e Valle (2009) argumentam ainda que o aumento no rigor da divulgação da informação facilita o acesso ao mercado de crédito, dada a redução do risco por parte dos credores, além de ocasionar a capitação de taxas mais atrativas. Essa situação se encaixa no atual momento vivido pelo setor de energia, que tem sido beneficiado com grande aporte de financiamentos.

Já com relação a proxy da assimetria que busca identificar as empresas nas quais o diretor executivo e o presidente do conselho são pessoas diferentes, o coeficiente da variável $\mathrm{DE}$, significativo também os três modelos em que foi inserida, teve um nível de significância de $1 \%$. $O$ resultado encontrado foi um coeficiente positivo, indicando que empresas em que o presidente do conselho e o CEO são pessoas diferentes tendem a se endividar mais. O resultado contraria o resultado esperado porque, como destaca IBGC (2010), o conselho de administração representa a ligação entre a propriedade e a gestão da empresa, tendo o objetivo de orientar e supervisionar a relação entre a gestão e as demais partes interessadas. Sendo assim, empresas em que o presidente do conselho e o CEO da empresa são pessoas diferentes tendem a ser menos passíveis deassimetria de informação, pois nesse caso se torna mais seguro o efetivo cumprimento do objetivo do conselho.

Almeida et al. (2013) argumentam ainda que empresas em que o CEO e o presidente do conselho são pessoas diferentes evitam a concentração de controle e, consequentemente, a assimetria de informação entre gestores e demais partes interessadas. Essa situação, contrária ao resultado esperado, pode ser mais uma vez explicada pelo setor em questão. A redução da assimetria de informação facilita a avaliação das empresas por parte dos credores, aumentando o acesso ao crédito, o que, no caso do setor de energia, se mostrou abundante no período estudado.

A variável binária ANEFAC, assumida como proxy da assimetria de informação, indica as empresas ganhadoras do Prêmio Troféu Transparência da Associação Nacional dos Executivos em Finanças, Administração e Contabilidade, ou seja, as que demonstraram mais transparência entre as concorrentes. Dessa forma, segundo Albanez e Valle (2009), tem-se uma importante proxy da assimetria de informação, visto que quanto maior a transparência, menor a possibilidade da assimetria de informação. $O$ coeficiente dessa variável foi significativo a $5 \%$ e positivo no primeiro modelo em que foi incluída. Nessa condição, compreende-se as que empresas ganhadoras desse troféu - ou seja, as menos passíveis de assimetria de informação - tendem a se endividar mais.

O resultado encontrado contraria, novamente, o esperado. Da mesma forma, essa situação pode ser explicada pelo momento vivido pelo setor durante o período de análise. Empresas ganhadoras do troféu transparência têm informações claras e objetivas divulgadas ao mercado, o que facilita a avaliação da empresa por parte de credores, facilitando o acesso ao crédito. Essa situação fica evidente ao se levar em conta a grande quantidade de crédito ofertado ao setor durante o período analisado. 
Finalizando a análise detalhada das proxies, passa-se à análise da variável Total1, que indica a quantidade de ações totais nas mãos do maior acionista. Essa variável foi assumida como proxy da assimetria, entendendo-se que uma quantidade grande de ações na mão de um único acionista leva à assimetria de informação, já que ele tem maior acesso às informações do que outros acionistas minoritários. O coeficiente dessa variável foi positivo nos dois primeiros modelos em que foi inserido, sendo significativo a $5 \%$ e $10 \%$ respectivamente. Tal fato corrobora o esperado, pois empresas com ações muito concentradas tendem a se endividar mais e são mais passíveis de assimetria de informação. Esse resultado confirma também a correlação positiva e significativa obtida anteriormente. Vale destacar, no entanto, que Procianoy e Schnorrenberger (2004) verificaram que empresas brasileiras de capital de aberto com propriedade concentrada tendem a se endividar menos.

\subsection{Setor têxtil}

Com relação ao setor têxtil, os modelos melhor ajustados foram os de efeitos aleatórios, como apontado pelo teste de Hausman, que apresentou $p$-valor de 0.996. Os modelos foram corrigidos por meio da estimação dos erros padrões robustos, com intuito de corrigir problemas heterocedasticidade, detectados por meio do teste de Wald, que apresentou $p$-valor $(0,00)$, rejeitando a hipótese nula de ausência de heterocedasticidade. Foi realizado também o teste de Wooldridgepara verificar a existência de autocorrelação. $O$ teste reportou o resultado de $p$-valor 0.788 , indicando ausência de autocorrelação. Foi verificado, ainda, a existência de multicolinearidade pelo Fator de Inflação da Variância, como mostra o Quadro 2.

Quadro 2 - Fator de Inflação da Variância para setor têxtil

\begin{tabular}{|l|l|}
\hline Variável & VIF \\
\hline Juros & 1.04 \\
\hline Risco & 1.24 \\
\hline Rentabilidade & 1.50 \\
\hline Tamanho & 1.86 \\
\hline Liquidez & 1.21 \\
\hline TCA & 1.62 \\
\hline Indep & 1.94 \\
\hline DE & 2.04 \\
\hline ANEFAC & 1.05 \\
\hline GC & 1.93 \\
\hline Total1 & 1.41 \\
\hline
\end{tabular}

Fonte: Elaborado pelos autores (2013)

Como verificado no Quadro 2, os valores do VIF indicam que não existem problemas de multicolinearidade, visto que nenhum valor foi superior a 10 .

Foram estimados oito modelos. Os seis primeiros contaram com as variáveis de controle e uma variável proxy da assimetria de informação. O último modelo foi composto por todas as variáveis de controle: Juros, Risco, Rentabilidade, Tamanho e Liquidez, além das variáveis proxies da assimetria, que são TCA, Indep, DE, ANEFAC, GC e Total1. Já o último modelo foi restrito às variáveis proxies de assimetria de informação, como segue: 


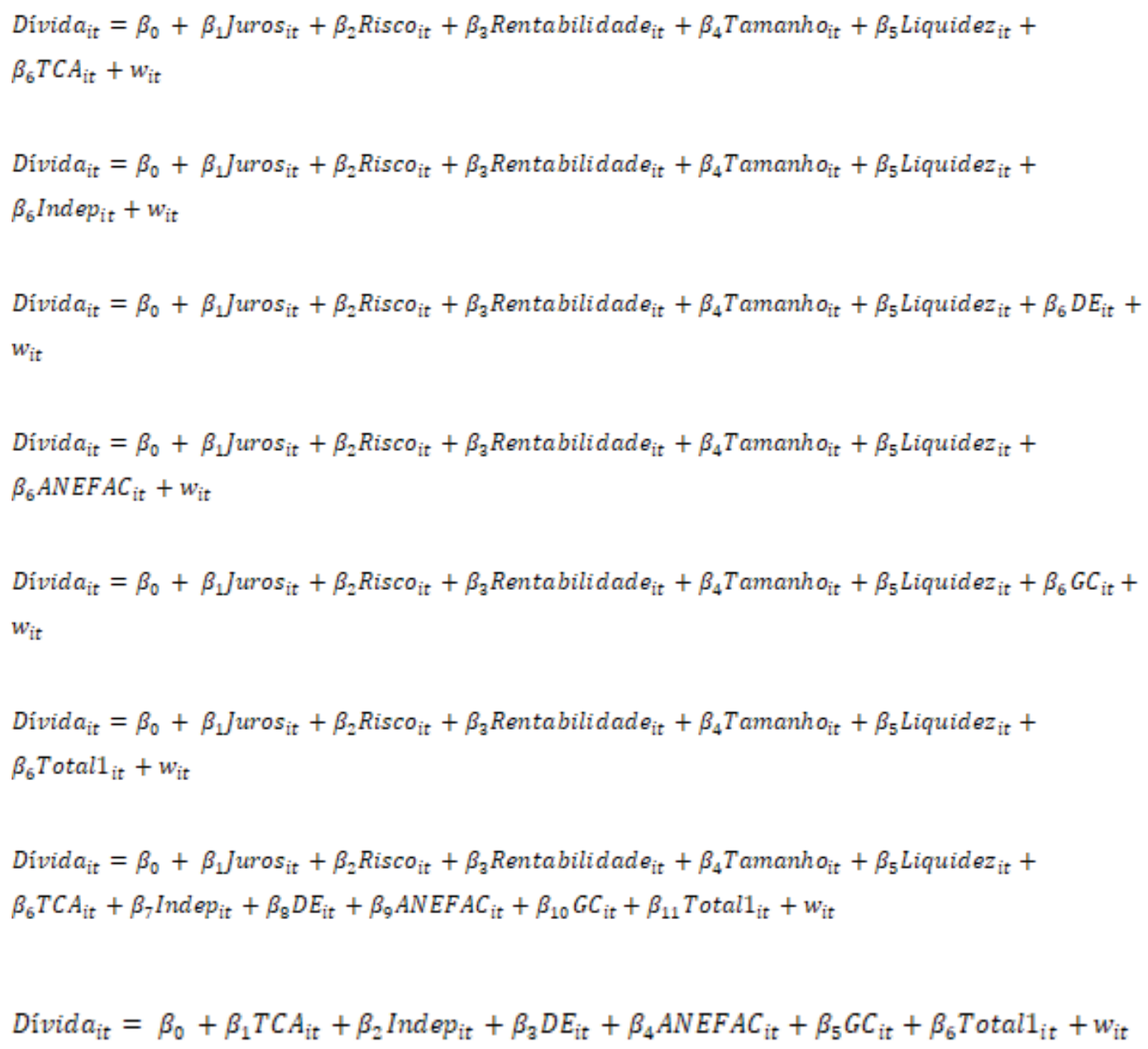

Ressalta-se que o setor têxtil apresentou um modelo a menos em relação ao setor de energia elétrica porque a variável ADR não foi contemplada em nenhum modelo. Tal fato ocorreu porque nenhuma empresa dessa amostra emite ações ou títulos na NYSE. A Tabela 2 apresenta os resultados da regressão com dados em painel por efeitos aleatórios, com correção do erro padrão robusto. 
ESTRUTURA DE CAPITAL E ASSIMETRIA DE INFORMAÇÃO:

UM ESTUDO EM EMPRESAS BRASILEIRAS DE CAPITAL ABERTO DOS SETORES TÊXTIL E DE ENERGIA ELÉTRICA

Tabela 02 - Modelo de Dados em Painel com efeitos aleatórios, corrigido pelo erro padrão robusto. Variável dependente: Dívida.

\begin{tabular}{|c|c|c|c|c|c|c|c|c|c|c|c|c|c|c|c|c|}
\hline \multirow[b]{2}{*}{$\begin{array}{l}\text { Variáveis Indepen- } \\
\text { dentes }\end{array}$} & \multicolumn{2}{|c|}{ Equação (1) } & \multicolumn{2}{|c|}{ Equação (2) } & \multicolumn{2}{|c|}{ Equação (3) } & \multicolumn{2}{|c|}{ Equação (4) } & \multicolumn{2}{|c|}{ Equação (5) } & \multicolumn{2}{|c|}{ Equação (6) } & \multicolumn{2}{|c|}{ Equação (7) } & \multicolumn{2}{|c|}{ Equação (8) } \\
\hline & Coef. & $\mathrm{p}$-valor & Coef. & p-valor & Coef. & p-valor & Coef. & $\mathrm{p}$-valor & Coef. & $\mathrm{p}$-valor & Coef. & $\mathrm{p}$-valor & Coef. & $\mathrm{p}$-valor & Coef. & $p$-valor \\
\hline Juros & -0.99 & 0.073 & -0.94 & 0.077 & -0.90 & 0.091 & -0.95 & 0.080 & -0.93 & 0.089 & -1.02 & 0.058 & -0.89 & 0.096 & & \\
\hline Risco & 8.53 & 0.172 & 8.58 & 0.170 & 8.67 & 0.172 & 8.56 & 0.173 & 8.91 & 0.162 & 7.42 & 0.175 & 7.78 & 0.167 & & \\
\hline Rentabilidade & -0.06 & 0.364 & -0.05 & 0.381 & -0.05 & 0.367 & -0.06 & 0.373 & -0.05 & 0.379 & -0.06 & 0.350 & -0.05 & 0.374 & & \\
\hline Tamanho & -2.52 & 0.683 & -2.65 & 0.673 & -2.34 & 0.700 & -2.29 & 0.710 & -1.62 & 0.796 & -1.76 & 0.766 & -1.44 & 0.82 & & \\
\hline Liquidez & -14.2 & 0.076 & -14.1 & 0.067 & -13.9 & 0.080 & -14.6 & 0.063 & -13.7 & 0.081 & -19.0 & 0.080 & -16.4 & 0.023 & & \\
\hline TCA & 0.48 & 0.702 & & & & & & & & & & & 0.39 & 0.834 & 0.03 & 0.999 \\
\hline Indep & & & 0.10 & 0.376 & & & & & & & & & 0.19 & 0.190 & 0.25 & 0.33 \\
\hline $\mathrm{DE}$ & & & & & -4.12 & 0.273 & & & & & & & -6.23 & 0.171 & -8.26 & 0.019 \\
\hline ANEFAC & & & & & & & -3.74 & 0.018 & & & & & -3.47 & 0.022 & -5.08 & 0.000 \\
\hline $\mathrm{GC}$ & & & & & & & & & -11.0 & 0.100 & & & -13.2 & 0.188 & -14.63 & 0.106 \\
\hline Total1 & & & & & & & & & & & -0.19 & 0.217 & -0.23 & 0.201 & -0.25 & 0.261 \\
\hline Constante & 67.60 & 0.434 & 62.86 & 0.455 & 69.0 & 0.418 & 67.15 & 0.435 & 0.107 & 0.484 & & & 54.02 & 0.534 & 27.09 & 0.125 \\
\hline \multirow[t]{2}{*}{ Observações } & \multicolumn{2}{|c|}{110} & \multicolumn{2}{|c|}{110} & \multicolumn{2}{|c|}{110} & \multicolumn{2}{|c|}{110} & \multicolumn{2}{|c|}{110} & \multicolumn{2}{|c|}{110} & \multicolumn{2}{|c|}{110} & \multicolumn{2}{|c|}{110} \\
\hline & \multicolumn{2}{|c|}{ Equação (1) } & \multicolumn{2}{|c|}{ Equação (2) } & \multicolumn{2}{|c|}{ Equação (3) } & \multicolumn{2}{|c|}{ Equação (4) } & \multicolumn{2}{|c|}{ Equação (5) } & \multicolumn{2}{|c|}{ Equação (6) } & \multicolumn{2}{|c|}{ Equação (7) } & \multicolumn{2}{|c|}{ Equação (8) } \\
\hline$F$ (p-valor) & \multicolumn{2}{|c|}{0.0077} & \multicolumn{2}{|c|}{0.0068} & \multicolumn{2}{|c|}{0.0075} & \multicolumn{2}{|c|}{0.0000} & \multicolumn{2}{|c|}{0.0101} & \multicolumn{2}{|c|}{0.0028} & & 00 & & 000 \\
\hline
\end{tabular}

Fonte: Elaborado pelos autores, 2013. 
Analisando a saída da regressão do setor têxtil, apresentada na Tabela 2, tem-se inicialmente que a o $p$-valor da estatística $F$ foi significativa a $1 \%$ para todos os modelos estimados. Inicialmente, foi analisado o modelo oito, que contou com as variáveis restritas às proxies de assimetria de informação. A construção desse modelo tem a mesma finalidade do construído anteriormente para o setor de energia, tendo por objetivo verificar se, de fato, as variáveis proxies da assimetria de informação interferem na estrutura de capital das empresas. O resultado do $p$ valor da estatística $F$ rejeita a hipótese nula, indicando que a assimetria de informação interfere na estrutura de capital.

Analisando inicialmente as variáveis de controle, tem-se que os coeficientes das variáveis Juros e Liquidez foram significativos. No caso da variável Juros, representada pela taxa Selic, essa foi significativa a $10 \%$ em todos os modelos estimados. O coeficiente negativo indica o esperado: 0 aumento da taxa de juros tende a diminuir a propensão ao endividamento, tornando-o mais caro.

Considerando a variável Liquidez, medida pela liquidez na Bovespa, essa também apresentou coeficiente significativo a $10 \%$ em todos os modelos, demonstrando sempre sinal negativo. O resultado confirma a correlação negativa com a variável dependente apresentada anteriormente, como esperado,, visto que, como argumentado por Agarwal e O'Hara (2007), títulos mais líquidos apresentam custos mais baixos de emissão e recompra de suas ações, levando a uma diminuição na alavancagem. Além disso, Bharath, Pasquariello e Wu (2009) ressaltam que empresas mais líquidas são menos passíveis de assimetria de informação, fato que contraria o endividamento. Tal resultado também foi encontrado nos trabalhos de Albanez e Valle (2009).

Com relação às proxies de assimetria informacional, a variável $\mathrm{DE}$, que leva em conta se o diretor executivo da empresa e o conselho de administração são pessoas diferentes, apresentou coeficiente negativo e significativo a $5 \%$. Esse resultado está de acordo com o esperado, pois empresas em que os cargos não se acumulam tendem a ser menos passíveis de assimetria de informação, indicando, então, que se endividam menos.

Já a variável binária ANEFAC, que lista as empresas ganhadoras do Troféu Transparência promovido pela Associação Nacional de Executivos de Finanças, Administração e Contabilidade (ANEFAC), apresentou coeficiente com significância de $5 \%$ nos dois primeiros modelos em que foi incluída e de $1 \%$ no oitavo modelo. O resultado foi um coeficiente negativo nas três regressões, o que se mostra de acordo com o esperado, já que empresas ganhadoras do prêmio tendem a ser menos passíveis de assimetria informacional, dada a transparência das informações e, consequentemente, têm uma tendência menor ao endividamento, como tratado por Albanez e Valle (2009).

Finalizando a análise dos dados em painel para as empresas do setor têxtil, a variável binária proxy da assimetria da informação GC, que apresenta as empresas que aderiram a algum nível de governança corporativa, apresentou coeficiente com significância de $10 \%$ no primeiro modelo. O resultado foi um coeficiente negativo, indicando que empresas que aderem a algum nível de governança têm uma média de endividamento menor. Esse resultado está de acordo com o esperado, pois empresas que aderem a algum nível de governança tendem a ser menos passíveis da assimetria informacional, o que contribui para um endividamento menor. Tal situação também foi encontrada por Albanez e Valle (2009).

O resultado mostra que, para o setor têxtil, reduções na assimetria levam ao aumento da utilização de recursos internos, situação contrária à verificada no setor de energia. Isso pode ser explicado pela situação de crise vivenciada pelo setor, o que aumenta o risco na contratação de crédito, dificultando o acesso à alavancagem. 


\section{CONSIDERAÇÕES FINAIS}

Diversas teorias apresentam fatores que podem servir como determinantes da estrutura de capital, dentre as quais encontra-se a Pecking Order. Essa teoria assume que a informação assimétrica é fator determinante para que as empresas escolham as fontes de financiamento das suas atividades. Ressalta-se, entretanto, que este trabalho não teve o objetivo de verificar a aplicação da Pecking Order, mas o de verificar se a assimetria de informação, fator central da POT, interfere na definição da estrutura de capital de empresas brasileiras de capital aberto, tanto do setor de energia elétrica e quanto do setor têxtil.

Os resultados obtidos apontam para uma resposta positiva para ambos os setores, rejeitando a hipótese nula estabelecida, considerando que os modelos estimados restritos às proxies de assimetria de informação apresentaram significância global. Além disso, no caso do setor de energia elétrica, apenas os coeficientes das proxies TCA e GC não foram significativos. A afirmação também pode ser feita para o setor têxtil, que mostrou coeficientes significativos das variáveis ANEFAC - também significativa no setor de energia elétrica - e GC, além da Liquidez, que, apesar de ter sido assumida como variável de controle, pode estar relacionada à assimetria de informação.

É importante ressaltar que, no caso do setor de energia elétrica, a assimetria de informação desempenha um papel diferente do previsto na Pecking Order. Como já destacado, essa teoria prevê que as fontes de financiamento que carregam menos assimetria informacional são preferíveis, indicando que se deve recorrer preferencialmente a fontes geradas internamente do que a dívidas. No caso do setor de energia elétrica, os resultados mostraram o contrário, indicando que empresas menos passíveis de assimetria de informação se endividam mais. A explicação pode residir no fato de que reduções na assimetria de informação ocasionam aumento da transparência da empresa frente aos credores, fator que atua como facilitador da oferta crédito. No caso do setor têxtil, a Pecking Order se apresenta com validade, tendo em vista que todas as variáveis proxies binárias significativas mostraram que empresas com menos tendência a informação assimétrica são menos endividadas, fato apontado pelas variáveis numéricas significativas.

A diferença no comportamento verificado nos dois setores com relação à Pecking Order pode estar relacionada com o momento vivido por eles: considerando o setor de energia, esse vive momento de pujança, sendo a oferta de crédito abundante durante o período analisado; sendo assim, a redução da assimetria leva a uma melhor avaliação por parte dos credores, o que facilita o acesso ao crédito, fazendo com que menor assimetria sinalize maior endividamento. Já o setor têxtil, como destacado, vive um momento de dificuldade, o que aumenta o risco de crédito e, consequentemente, dificulta a sua contratação, fazendo com que os resultados encontrados corroborem a teoria de que uma redução na assimetria de informação leva à preferência por recursos internos. Além disso, destaca-se que o setor de energia é alvo de forte regulação pela ANEEL, o que pode fazer com que a assimetria de informação tenha um impacto diferente na estrutura de capital quando comparada ao setor de energia elétrica. 


\section{REFERÊNCIAS}

ABINEE - Associação Brasileira da Indústria Elétrica e Eletrônica. Desempenho Setorial. Disponível em: <http://www.abinee.org.br/abinee/decon/decon15.htm> Acesso em: 10 de set. de 2013.

ALBANEZ, T.; VALLE, M. R. D. Impactos da assimetria de informação na estrutura de capital de empresas brasileiras abertas. Revista Contabilidade \& Finanças, v. 20, p. 6-27, 2009. ISSN 15197077.

ALMEIDA, R. S. et al. Composição do Conselho de Administração no Setor de Energia Elétrica do Brasil. Revista de Administração da Unimep, v. 11, n. 1, p. 156-180, 2013.

ANDRADE, A; ROSSETTI, J.P. Governança corporativa: fundamentos, desenvolvimento e tendências. São Paulo: Ed. Atlas, 2004.

ASSAF NETO, A. A. Finanças corporativas e valor. São Paulo: Atlas, 2003.

BAHNEMANN, W. BNDES prevê desembolsar R\$ 19 bi para elétricas em 2013. Exame.com. Disponível em: <http://exame.abril.com.br/economia/noticias/bndes-preve-desembolsar-r-19bi-para-eletricas-em-2013>. Acesso em: 12 de set. de 2013.

BHARATH, S. T.; PASQUARIELLO, P.; WU, G. Does Asymmetric Information Drive Capital Structure Decisions? Reviewof Financial Studies, v. 22, n. 8, p. 3211-3243, 2009.

BRITO, G. A. S.; CORRAR, L. J.; BATISTELLA, F. D. Fatores determinantes da estrutura de capital das maiores empresas que atuam no Brasil. Revista Contabilidade e Finanças, p. 9-19, 2007.

COASE, R. H. The nature of the firm. Economica, v. 4, n. 16, p. 386-405, 1937.

DIESSE - Departamento Intersindical de Estatística e Estudos Sócio-Economicos. Boletim do Setor Elétrico. Disponível em:

<http://www.dieese.org.br/estudosetorial/2013/boletimSetorEletricoN1.pdf>. Acesso em: 10 de set. de 2013.

DANTAS, R. F.; SOUZA, S. A. Modelo de risco e decisão de crédito baseado em estrutura de capital com informação assimétrica. Pesquisa Operacional, v. 28, n. 2, p. 263-284, 2008.

DA COSTA, A. C. R.; DA ROCHA, E. R. P. Panorama da cadeia produtiva têxtil e de confecções e a questão de inovação. BNDES Setorial, n. 29, p. 159-202, 2009.

FAMA, E. F.; JENSEN, M. C. Separation of ownership and control. Journal of Law and Economics, v. 26, n. 2, p. 301-325, 1983.

FAMA, E. F.; FRENCH, K. R. Testing Trade-Off and Pecking Order predictions about dividends and debt. Review of Financial Studies, v. 15, n. 1, p. 1-33, January 1, 2002.

FAMÁ, R.; BARROS, L.; SILVEIRA, A. A Estrutura de Capital é Relevante? Novas Evidências a partir de dados norte-americanos e latino-americanos. Caderno de Pesquisas em Administração, v. 8, n. 2, p. 71-84, 2001.

FAMÁ, R.; GRAVA, J. W. Teoria da estrutura de capital: as discussões persistem. Caderno de 
Pesquisas em Administração, v. 1, n. 11, p. 27-36, 2000.

FRANK, M. Z.; GOYAL, V. K. Testing the pecking order theory of capital structure. Journal of Financial Economics, v. 67, n. 2, p. 217-248, 2003. ISSN 0304-405X.

GUGLER, K.; YURTOGLU, B. B. Corporate governance and dividend pay-out policy in Germany. European Economic Review, v. 47, n. 4, p. 731-758, 2003.

GUJARATI, D. Econometria Básica. Tradução de Maria José Cyhlar Monteiro: Rio de Janeiro: Elsevier, 2006.

HALOV, N.; HEIDER, F. Capital structure, asymmetric information and risk. NYU Stern School of Business Working Paper, 2003.

HARRIS, M.; RAVIV, A. The theory of capital structure. The Journal of Finance, v. 46, n. 1, p. 297355, 1991.

HSIAO, C. Analysis of panel data. Cambridge: Cambridge University Press, 1986.

IBGC - Instituto Brasileiro de Governança Corporativa. Código das melhores práticas de governança corporativa. Versão 2010. Disponível em <http://www.ibgc.org.br>. Acesso em: 02 de fev. de 2013.

IEMI - Instituto de Estudos e Marketing Industrial. Relatório Setorial da Indústria Têxtil Brasileira. Brasil Têxtil. São Paulo, 2013.

IQUIAPAZA, R. A.; LAMOUNIER, W. M.; AMARAL, H. F. Assimetria de Informações e Pagamento de Proventos na Bovespa. Munich Personal RePEc Archive. MPRA Paper, n. 1673, nov. 2007.

JENSEN, M. C.; MECKLING, W. H. Theory of the firm: Managerial behavior, agency costs and ownership structure. Journal of Financial Economics, v. 3, n. 4, p. 305-360, 1976.

MILGROM, P. R.; ROBERTS, J. Economics, organization and management. Englewood Cliffs, NJ: Prentice-Hall, 1992.

MODIGLIANI, F.; MILLER, M. H. The cost of capital, corporation finance and the theory of investment. The American Economic Review, v. 48, n. 3, p. 261-297, 1958.

Corporate income taxes and the cost of capital: a correction. The American Economic Review, v. 53, n. 3, p. 433-443, 1963.

MYERS, S. C. The Capital Structure Puzzle. The Journal of Finance, v. 39, n. 3, p. 575-592, 1984. ISSN 00221082.

MYERS, S. C. Capital structure. Journal of Economic Perspectives, v. 15, n. 2, p. 81-102, 2001.

MYERS, S. C.; MAJLUF, N. S. Corporate financing and investment decisions when firms have information that investors do not have. Journal of Financial Economics, v. 13, n. 2, p. 187-221, 1984. ISSN 0304-405X.

NAKAMURA, W. T. et al. Determinantes de estrutura de capital no mercado brasileiro: análise de regressão com painel de dados no período 1999-2003. Revista Contabilidade e Finanças, p. 72-85, 2007. 
NEWEY, W.; WEST, K. A Simple Positive Semi-Definite, Heroskedasticity and Autocorrelation Consistent Covariance Matrix. Econométrica, v.55, p.703-708, 1987.

PROCIANOY, J. L.; SCHNORRENBERGER, A. A influência da estrutura de controle nas decisões de estrutura de capital das companhias brasileiras. Revista Brasileira de Economia, v. 58, p. 122146, 2004. ISSN 0034-7140.

ROSS, S. A. The economic theory of agency: The principal's problem. The American Economic Review, v. 63, n. 2, p. 134-139, 1973.

SHLEIFER, A.; VISHNY, R. W. A Survey of Corporate Governance. The Journal of Finance, v. 52, n. 2, p. 737-783, 1997.

SILVEIRA, A. D. M. Governança corporativa e estrutura de propriedade: determinantes e relação com o desempenho das empresas no Brasil. 1ạ ed. São Paulo: Saint Paul Institute of Finance, 2006.

SILVEIRA, A. D. M. D.; PEROBELLI, F. F. C.; BARROS, L. A. B. D. C. Governança Corporativa e os determinantes da estrutura de capital: evidências empíricas no Brasil. Revista de Administração Contemporânea, v. 12, p. 763-788, 2008.

VENTURA FILHO, A. Energia Elétrica no Brasil: Contexto Atual e Perspectivas. Interesse Nacional, n. 21, abr-jun. 2013. Online. Disponível em:

$<$ http://interessenacional.uol.com.br/index.php/edicoes-revista/energia-eletrica-no-brasilcontexto-atual-e-perspectivas/6/> Acesso em: 12 de set. de 2013.

WILLIAMSON, O. E. The Economic Institutions of Capitalism. New York: The Free Press, 1985.

WOOLDRIDGE, J. M. Introdução à econometria: uma abordagem moderna. Pioneira Thomson Learning, 2006. 